This is a pre-copyedited, author-produced version of an article accepted for publication in Journal of Animal Science following peer review. The version of record "Vitali, M., Conte, S., Lessard, M., Deschêne, K., Benoit-Biancamano, M. 0., Celeste, C., Martelli, G., Sardi, L., Guay, F. \& Faucitano, L. (2017). Use of the spectrophotometric color method for the determination of the age of skin lesions on the pig carcass and its relationship with gene expression and histological and histochemical parameters. Journal of animal science, 95(9), 3873-3884." is available online at:

https://academic.oup.com/jas/article/95/9/3873/4702472; DOI https://doi.org/10.2527/jas.2017.1813 


\title{
Use of the spectrophotometric color method for the determination of the age of skin lesions on the pig carcass and its relationship with gene expression and histological and histochemical parameters ${ }^{1}$
}

\author{
M. Vitali, $* 2$ S. Conte,$\dagger^{3}$ M. Lessard, $\dagger$ K. Deschêne, $\dagger$ M.O. Benoit-Biancamano, \\ C. Celeste,§ G. Martelli,* L. Sardi,* F. Guay,\# and L. Faucitano $\uparrow$

\begin{abstract}
*Department of Veterinary Medical Sciences, University of Bologna, I-40064 Ozzano dell’Emilia, Italy; †Agriculture and Agri-Food Canada, Sherbrooke Research and Development Centre, Sherbrooke, QC J1M 0C8, Canada; \$Department of Pathology and Microbiology, Faculty of Veterinary Medicine, University of Montréal, Saint-Hyacinthe, QC J2S 2M2, Canada; §Department of Veterinary Biomedicine, Faculty of Veterinary Medicine, University of Montréal, Saint-Hyacinthe, QC J2S 2M2, Canada; and \#Department of Animal Science, Université Laval, Québec, QC G1V 0A6, Canada
\end{abstract}

\begin{abstract}
The presence of lesions on the pig carcass is an indicator of poor animal welfare and has economic impact as it downgrades the carcass value. The assessment of the age of lesions on the carcass may help identify risk factors and ultimately prevent their occurrence. The aim of this study was to assess the age of lesions on pig carcasses through spectrophotometric color evaluation and to relate the results with gene expression and histological and histochemical parameters. A total of 96 barrows were mixed 4 times over $3 \mathrm{~d}$ before slaughter and 80 lesions were selected after skin lesion observations to define 4 age categories: $<7 \mathrm{~h}$ (T1), 7-25 h (T2), 25-30 h (T3), and 49-54 h (T4). A nonlesioned skin area was used as a control. At slaughter, 3 biopsies per lesion and control skin were taken immediately after bleeding for analyses of gene expression (CCL2, COX2, IL6, IL8, IL10, ITGA3, MMP1, TNF, TIMP1, SERPINE1), skin histological characteristics (inflammation, erosion or ulceration, and necrosis), and enzyme activity (alkaline phosphatase and adenosine triphosphatase). The number of lesions was counted on each carcass,
\end{abstract}

and the color was assessed visually by a pictorial chart and instrumentally through a spectrophotometer. Delta values $(\Delta)$ were calculated as the difference between the value of the lesion and the value of the control for all measures, except for the histological analysis. Results indicated that visual color observation was not sufficiently accurate to discriminate lesions by time of infliction $(P>0.10)$, while the spectrophotometer $\Delta \mathrm{L}^{*}$ and $\Delta \mathrm{a}^{*}$ values variation allowed the identification of $<7 \mathrm{~h}$ or $>25 \mathrm{~h}$ old lesions $(P<$ 0.05). Similarly, the expression of CCL2, IL6, ITGA3, $M M P 1$, and SERPINE1 genes was higher $(P<0.05)$ in $<7 \mathrm{~h}$ old lesions, while TIMP1 gene expression was higher $(P<0.05)$ in $<25$ h old lesions. As for the histological analysis, the severity of inflammation was correlated with the age of the lesion (lower score in $<$ $7 \mathrm{~h}$ old lesions and higher score in $>25 \mathrm{~h}$ old lesions; $P<0.05)$. To conclude, the spectrophotometric color assessment of the carcass lesions at slaughter appears to be a reliable method to discriminate between fresh and older lesions on the carcass at the abattoir.

Key words: color assessment, enzyme histochemistry, gene expression, histology, pig carcass, skin lesion age

\footnotetext{
${ }^{1}$ This research project was funded by Swine Innovation Porc within the Swine Cluster 2: Driving Results Through Innovation research program. Funding was provided by Agriculture and Agri-Food Canada through the Agri Innovation Program, provincial producer organizations, and industry partners. The authors thank Janaina Braga, Davide Carbonari, Ariane de Castro, Taciana Diesel, and Fidèle Z. Kabemba for their valuable contribution to the data collection at the farm and abattoir. Many thanks go to Catherine Thibault and Mylène Blais for their contributions to the gene analysis, Steve Méthot for his assistance in the statisti-
}

cal analysis, and to the staff of the AAFC swine unit for the care of animals, performed with expertise and professionalism. We are grateful to the COOP Fédérée for supplying pigs and feed, and to the Rousseau abattoir staff for their collaboration during the slaughter trials. The authors declare no conflict of interest.

${ }^{2}$ Present address: Interdepartmental Centre for Industrial Agrifood Research, University of Bologna, I-47521 Cesena, Italy

${ }^{3}$ Corresponding author: Sabine.Conte@agr.gc.ca 


\section{INTRODUCTION}

The presence of skin lesions is an animal-based criterion in the animal welfare assessment (Welfare Quality, 2009; EFSA Panel on Animal Health and Welfare, 2012) and an economical issue resulting in reduced profits due to carcass downgrading (MLC, 1985) and additional handling for carcass inspection (Faucitano, 2001). Common causes of skin lesions on the pig carcass are poor housing, mixing of unfamiliar pigs, and rough handling (Faucitano, 2001). Lesions are commonly assessed on the carcass using pictorial standards (MLC, 1985) or by giving a score based on their number and type (ITP, 1996; Welfare Quality, 2009). However, no reliable technique exists for the determination of the age of skin lesions in pigs. As injuries can occur at any moment during the marketing process (dalla Costa et al., 2007; Aaslyng et al., 2013), knowing the time of infliction may be very helpful to reduce or prevent their occurrence. The most common method for assessing lesion age at the abattoir is by visual color assessment (Rocha et al., 2013), which, however, may be biased by human error (Scafide, 2012). Objective evaluation of lesion color using spectrophotometry, molecular biology, and histological and histochemical techniques has been studied in different livestock species (Hamdy et al., 1957; Strappini et al., 2009; Munro and Munro, 2013) and in forensic medicine using human and animal models (Wang et al., 2001, Gallant-Behm and Hart, 2006; Kondo and Ishida, 2010; Barington and Jensen, 2016a,b). Despite the need for a reliable assessment of the age of lesions on the pig carcass at slaughter (Barington and Jensen, 2013), to our knowledge, an objective technique applicable on the pig carcass under marketing conditions is still missing.

The objective of the study was to provide a reliable determination of the age of lesions on pig carcasses at the abattoir through objective color assessment and to relate the results with biological indicators, such as expression of genes, histological parameters, and enzyme histochemistry.

\section{MATERIALS AND METHODS}

All experimental procedures performed in this study were approved by the institutional animal care committee at the Agriculture and Agri-Food Canada (AAFC) Sherbrooke Research and Development Centre (Sherbrooke, QC, Canada) based on the current guidelines of the Canadian Council on Animal Care (CCAC, 2009).

\section{Animals and Handling}

A total of 96 crossbred barrows (Piétrain x [Large White $\mathrm{x}$ Landrace]) were distributed into 8 pens of 12 pigs (4 replicates of 2 groups; $124.2 \pm 1.7 \mathrm{~kg}$ average body weight). Animals were kept at the AAFC swine unit in Sherbrooke (QC, Canada). Pigs from each replicate, corresponding to 2 pens, were mixed 3 times over the $3 \mathrm{~d}$ before of slaughter: twice at the farm (2 $\mathrm{d}$ before slaughter and the day prior to slaughter) and once at loading. The first mixing consisted of randomly grouping 6 pigs from the first pen with 6 pigs from the second pen to create 2 new groups of 12 pigs each. The second mixing involved the remaining 6 pigs left in each pen and that had never met before. For the third mixing, all pigs (24) were grouped at loading and in lairage.

Before and $3 \mathrm{~h}$ after the first and second mixing events, skin lesions were scored according to the Welfare Quality Protocol for pigs (Welfare Quality, 2009) by 2 trained observers. At the same time, lesions on all pigs were mapped on both sides of a pig body image printed on a paper and marked with different colors according to the 6 observational sessions (performed before and after each mixing) to trace back the exact time of the lesion's appearance. A video of each pig body was also recorded to validate the visual observation.

Biting- and mounting-type lesions, characterized by short comma or long scratch shapes, respectively, are those most commonly observed on the pig carcass at slaughter (Varón-Álvarez et al., 2014). Hence, only these types of lesions were considered in this study. Two parallel scratches of at least $2.5-\mathrm{cm}$ length and 4-mm width were considered as 1 lesion. Lesions on the head, ears, abdomen, legs, and tail were not considered because of the risk of being caused by postmortem carcass handling procedures. Just prior to slaughter, 80 lesions, distributed into 4 age categories, were selected (20 lesions per age category) based on the time of their appearance on the pig body and slaughter time (time 0$)$ as follows: T1 $(<7 \mathrm{~h}$ old), T2 (7-25 h old), T3 (25-30 h old), and T4 (49-54 h old). The T1 lesions corresponded to fresh lesions inflicted during loading, transport, and/or lairage, while the other lesions (T2, T3, and T4) corresponded to lesions inflicted during mixing at the farm. To ease skin sampling, body areas with a selected lesion were carefully hair clipped and individually identified by a colored circle right before slaughter.

Pigs were subjected to a $12 \mathrm{~h}$ fasting before being transported to a slaughterhouse located at $45 \mathrm{~min}$ from the AAFC swine unit. At the slaughterhouse, pigs were kept in lairage for approximately $3.5 \mathrm{~h}$ (excluding $1 \mathrm{~h}$ of skin lesion observation in the pen made $1 \mathrm{~h}$ after the start of lairage) and slaughtered by exsanguination in the prone position after head-only electrical stunning. 


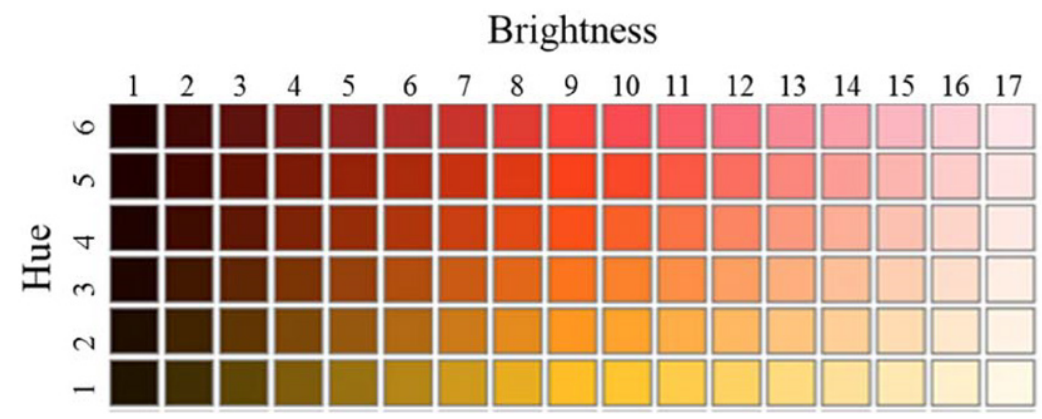

Figure 1. Visual color assessment scale used to describe the color of both lesion and intact skin (control).

\section{Sample Collection and Measurements}

Immediately after exsanguination, 3 biopsies per lesion were collected on 1 of 2 parallel scratches from the 80 selected lesions (20 lesions for the 4 age categories) and on nonlesioned skins (control), sampled from the same pig and in the area surrounding the sampled lesion, using 4-mm diameter disposable biopsy punches (Integra Miltex, York, PA). A sample for histological analysis was fixed in a $10 \%$ buffered formalin solution and 1 sample was embedded in an optimum cutting temperature (O.C.T.) compound for histochemical enzyme analysis, then snap-frozen in liquid nitrogen and later stored at $-80^{\circ} \mathrm{C}$. A third sample was snap-frozen in liquid nitrogen and stored at $-80^{\circ} \mathrm{C}$ pending real-time PCR mRNA analysis.

In the cooler, the number of lesions was counted on each carcass using an adapted version of the Welfare Quality Protocol for Pigs (Welfare Quality, 2009), excluding the ears from the count as they were removed during carcass processing. Skin damages that may have been caused by carcass processing (i.e., dehairing) were also excluded from the count. Carcasses were classified using a scale from 0 (up to 4 lesions on the whole body) to 2 ( $>11$ lesions in 2 body regions or at least 15 lesions in 1 body region) according to the Welfare Quality Protocol (Welfare Quality, 2009). The lesion and nonlesioned skin colors were first assessed visually using a scale of hue and brightness values (Fig. 1), and a photo of each lesion was taken for further validation. Color was then measured 3 times at 3 different positions along each lesion (on the nonbiopsied parallel scratch) as well as on the nonlesioned skin using a CM 700d Spectrophotometer (Konica Minolta Sensing Inc., Osaka, Japan). The measures were taken using an $8^{\circ}$ viewing angle, a $2^{\circ}$ observer angle, D65 illuminant, specular component included (SCI) mode, with an illumination measurement area of $3 \mathrm{~mm}$ in diameter. CIE $\mathrm{L} * \mathrm{a} * \mathrm{~b} *$ color coordinates were used.

\section{Histological and Histochemical Analyses}

Histology. Biopsy samples were cut into 2, routinely processed and embedded in paraffin (TissuePrep $2 \mathrm{Mi}$ cron; Fisher Scientific, Ottawa, ON, Canada). Sections of 4- $\mu \mathrm{m}$ thickness were deparaffinized and then stained with hematoxylin-eosin-phloxin-saffron (HEPS) to score 4 parameters: inflammation, erosion/ulceration, hemorrhage, and necrosis of the derma and epidermis.

Alkaline Phosphatase (ALPase). Samples were cut into 4- $\mu \mathrm{m}$ sections in a Leica CM3050S research cryostat (Leica Biosystems, Concord, ON, Canada) at $-24^{\circ} \mathrm{C}$. Alkaline Phosphatase Staining (Red) Kit (Cell Biolabs Inc., San Diego, CA) was used. The specimens were stained with StemTAGTM AP Staining solution and incubated at room temperature for 15 to 30 min, protected from light. Slides were counterstained with $0.1 \%$ Fast Green. Alkaline phosphatase activity appeared as a reddish stain on a turquoise background.

Adenosine Triphosphatase (ATPase). Samples were cut into $4-\mu \mathrm{m}$ sections in cryostat at $-24^{\circ} \mathrm{C}$ and stained at $\mathrm{pH} 9.4$ following the method described by Bancroft (1975). Slides were counter-stained with Harris hematoxylin for $25 \mathrm{~s}$, then were rinsed with distilled water. Dehydration was performed as follows: $80 \%$ alcohol for $2 \mathrm{~min}, 95 \%$ alcohol for $2 \mathrm{~min}, 100 \%$ alcohol for $2 \mathrm{~min}$, and toluol for $5 \mathrm{~min}$. Slides were mounted with a Leica CV 5000 automated cover slipper (Leica Biosystems, Concord, ON, Canada).

Microscopic Examination. Microscopic examination for HEPS and histochemistry stains was performed with an Olympus BX41 optical microscope (Olympus America Inc., Melville, NY). Magnification of 25 to $400 \mathrm{X}$ was used as appropriate. For inflammation, hemorrhage, epidermal ATPase, and dermal and epidermal ALPase (ALPaseD and ALPaseE, respectively), the following grading system was used to describe lesions: 0 = absent, $1=$ minimal, $2=$ mild, $3=$ moderate, and $4=$ severe. For epidermal erosion/ulceration and necrosis, this grading was modified and expressed as the percentage of epidermal surface of the sample section being affected: no grade $=0 \%$ of the epidermis, $1=<25 \%, 2$ $=25-50 \%, 3=>50-75 \%, 4=>75-100 \%$. 
Table 1. PCR primer sequences of genes used in this study

\begin{tabular}{|c|c|c|c|}
\hline Gene & Primer & Dilution, $\mathrm{nM}$ & Sequence number \\
\hline \multirow[t]{2}{*}{$\overline{\mathrm{CCL} 2}$} & F CTGCACCCAGGTCCTTGCCC & 300 & NM_214214 \\
\hline & R CTGCTGGTGACTCTTCTGTAG & 300 & \\
\hline \multirow[t]{2}{*}{ IL6 } & F GGAAATGTCGAGGCTGTGCAGATT & 300 & NM_214399.1 \\
\hline & R GGTGGTGGCTTTGTCTGGATTCTT & 300 & \\
\hline \multirow[t]{2}{*}{$\operatorname{cox} 2$} & F AAGCGAGGACCAGCTTTCACCAAA & 300 & NM_214321.1 \\
\hline & R GCGCAGTTTATGCTGTCTCTCCAA & 300 & \\
\hline \multirow[t]{2}{*}{ ITGA3 } & F ATCATTTGCGAGCTGGGGAAC & 50 & XM_005668880 \\
\hline & R CAGCTGCGCCTGGAGTTC & 50 & \\
\hline \multirow[t]{2}{*}{ MMP1 } & F TGCCAAATGGACTTCAAGCTGC & 300 & NM_001166229 \\
\hline & R GATCTGTGGATGTCCTTGGGG & 300 & \\
\hline \multirow[t]{2}{*}{ TIMP1 } & F ACCAAGATGTTCAAAGGGTTCAAT & 300 & NM_213857 \\
\hline & R TCCGCAGACGCTCTCCAT & 300 & \\
\hline \multirow[t]{2}{*}{ IL8 } & F AGAACTGAGAAGCAACAACAACAG & 300 & NM_213867.1 \\
\hline & R CACAGGAATGAGGCATAGATGTAG & 300 & \\
\hline \multirow[t]{2}{*}{$\mathrm{TNF} \alpha$} & F CACTGACCACCACCAAGAATTGGA & 300 & NM_214022.1 \\
\hline & R CATTCCAGATGTCCCAGGTTGCAT & 300 & \\
\hline \multirow[t]{2}{*}{ SERPINE1 } & F CCACCCCCGACGGCCATTAC & 300 & NM_213910.1 \\
\hline & R TGGTGAGGGCGGAGAGAGGC & 300 & \\
\hline \multirow[t]{2}{*}{ IL10 } & F GATATCAAGGAGCACGTGAACTC & 300 & NM_214041.1 \\
\hline & R GAGCTTGCTAAAGGCACTCTTC & 300 & \\
\hline \multirow[t]{2}{*}{$\mathrm{B} 2 \mathrm{M}$} & F GGATCAGTATAGCTGCCGCG & 300 & NM_213978.1 \\
\hline & R TCTGTGATGCCGGTTAGTGG & 300 & \\
\hline \multirow[t]{2}{*}{ RPS18 } & F CATGTGGTGTTGAGGAAAGCA & 300 & NM_213940.1 \\
\hline & R TTGGCGAGGATTCTGCATAAT & 150 & \\
\hline
\end{tabular}

\section{Gene Expression Analysis}

A sample $(30 \mathrm{mg}$ ) was collected from the thawed skin punches and homogenized in RLT buffer and mercaptoethanol. Total RNA was extracted following the RNA Extraction Fibrous Mini Kit (Qiagen, Hamburg, Germany) protocol and eluted in $30 \mu \mathrm{L}$ of nuclease-free water. All samples were quantified through a NanoDrop Spectrophotometer (NanoDrop Technologies Inc., Wilmington, DE) at a wavelength of $260 \mathrm{~nm}$; the minimum accepted value to proceed with Reverse-Transcription was $62 \mathrm{ng} / \mu \mathrm{L}$. The quality of RNA was assessed through a bioanalyzer with Agilent RNA quality 6000 Nano Kit (Agilent Technologies, Waldbronn, Germany). Obtained values of RNA integrity number $($ RIN) $>8$ confirmed that the RNA quality was adequate for the real-time PCR analysis. The cDNA synthesis was performed with $1 \mu \mathrm{g}$ of RNA using the RT2 First Strand Kit (Qiagen, Hamburg, Germany) to obtain $20 \mu \mathrm{L}$ of cDNA solution diluted to a concentration of $1: 15 \mu \mathrm{L}$ in nuclease-free water. Real-time PCR was performed using Step One Plus Real-Time PCR System (Applied Biosystems, Framingham, MA) to evaluate the mRNA modulation for the 12 genes listed in Table 1. Of these genes, 10 were the target genes (CCL2, IL6, ITGA3, SERPINE1, $M M P 1, T I M P 1, T N F \alpha, I L 8, I L 10$, and COX2) that were previously selected out of 94 genes analyzed for their efficiency in skin lesion age determination in a preliminary study on live pigs (Vitali et al., 2017). Primers were designed using known pig sequences for the genes of interest (Table 1). Real-time PCR amplification was started with an initial 10-min enzyme activation stage at $95^{\circ} \mathrm{C}$, followed by 40 cycles of $15 \mathrm{~s}$ denaturation at $95^{\circ} \mathrm{C}$ and $1 \mathrm{~min}$ annealing and extension at $60^{\circ} \mathrm{C}$. Each sample was analyzed in triplicate. The fold change in the expression of the 10 target genes was calculated using the $2^{-\Delta \Delta} \mathrm{CT}$ method (Livak and Schmittgen, 2001) and B2M and RPS18 as housekeeping genes and nonlesioned skin samples as a control.

\section{Statistical Analysis}

Visual Color Assessment. Delta values ( $\Delta$ hue and $\Delta$ brightness) were calculated as the difference in color values between the lesion and the control skin. Data were analyzed in SAS (SAS Inst. Inc., Cary, NC) using the Kruskal-Wallis test including the 4 age categories in the model. Values are reported as median (lower and upper quartiles in brackets).

Spectrophotometric Color Assessment. The 3 spectrophotometer $\mathrm{L}^{*}, \mathrm{a}^{*}, \mathrm{~b}^{*}$ color values of each lesion were averaged and a delta value $\left(\Delta \mathrm{L}^{*}, \Delta \mathrm{a}^{*}\right.$, and $\left.\Delta \mathrm{b}^{*}\right)$ was obtained by calculating the difference between the color measure taken on the lesion and the 
control skin. Delta values were analyzed in SAS using the MIXED procedure including the lesion age categories as fixed effect in the model. Multiple comparisons were made using the Tukey adjustment. Data are presented as $\mathrm{LSM} \pm \mathrm{SEM}$. Moreover, the accuracy of the spectrophotometric measures for the determination of the age of a lesion was evaluated as described by Parikh et al. (2008). Briefly, this method consists of comparing the classification of the lesion age obtained with a measure (e.g., $\Delta \mathrm{L}^{*}$ ) with the real age of the lesion (based on direct observations of the lesion appearance on live pigs after each mixing event). To select the best threshold value above or below which the lesion would be correctly classified as fresh or old, sensitivity, specificity, and the positive predictive value (PPV: the probability that the lesion is actually fresh when the indicator is above a certain value) were calculated for several threshold values. The higher the sum of sensitivity, specificity, and PPV, the more accurate a threshold was for the lesion age classification. The negative predictive value (NPV: the probability that the lesion is old when the indicator is below the threshold value) of the indicators was also calculated (Parikh et al., 2008).

Histology. For technical reasons, histological data from 2 lesions in the $\mathrm{T} 4$ age category were missing. To reduce the number of ordinal categories and increase statistical power, grades were combined as follows: score $0=$ grade 0 ; score $1=$ grades 1 and 2 ; score 2 $=$ grades 3 and 4 . The relationship between necrosis, erosion, inflammation, and hemorrhage score and age categories was assessed using the Cochran-MantelHaenszel test of association for ordinal categories (row mean score statistic). In the case of a significant association, multiple comparisons (6 comparisons) were made using a Bonferroni adjusted $P$-value $(P<0.008)$.

Enzyme Histochemistry. Delta values were calculated as the difference between the grades of the lesion and of the control ( $\triangle$ ATPase, $\triangle$ ALPaseE, and $\triangle \mathrm{ALPaseD})$. Delta values were then re-categorized into score 0 if the delta was 0 , score 1 if the delta was 1 or 2 , and score 2 if the delta was 3 or 4 . The relationship between the score for each enzyme and the age categories was assessed using the Cochran-Mantel-Haenszel test of association for ordinal categories (row mean score statistic).

Gene Expression. For technical reasons, gene expression data from 1 lesion in the T3 age category were missing. The fold change value for each cytokine was log-transformed and analyzed using the MIXED procedure of SAS including the lesion age categories as fixed effect in the model. Multiple comparisons were made using the Tukey-Kramer adjustment. Back-transformed values are reported as means with lower and upper limits in squared brackets.
Multivariate Analysis. A Factorial Analysis of Mixed Data (FAMD) was performed with the PRINCOMP procedure of SAS on selected variables related to the lesion age categories to analyze relationships among these variables and the lesion age category. The categorical variables were transformed into a complete disjunctive table and included in the PCA analysis along with the centered and scaled matrix of numerical variables.

For all analyses, the experimental unit was the skin lesion $(n=80)$. A probability level of $P<0.05$ was chosen as the limit for statistical significance in all tests, whereas probability levels of $P \leq 0.10$ were considered to be a tendency.

\section{RESULTS AND DISCUSSION}

\section{Lesion Score}

According to Hamdy et al. (1957), the number of lesions on the body can influence the speed of physiological responses in the healing process. In this study, all carcasses selected for the lesion assessment presented the same high score (score 2) for the number of lesions. Therefore, the number of lesions on the body similarly influenced the healing process of all the selected lesions and so this factor did not bias the results in this study.

\section{Color Assessment}

Overall, the visual color assessment showed that the lesions were darker (- $\Delta$ brightness; $P|\mathrm{t}|<0.001)$ with a redder hue $(-\Delta$ hue; $P|\mathrm{t}|<0.001)$ than the nonlesioned skin (Table 2). However, the visual assessment failed to find differences in these color parameters between age categories $(P>0.10)$, confirming the inaccuracy of this method for lesion age determination as already reported in previous studies (Hughes et al., 2004a; Barington and Jensen, 2013).

The spectrophotometric color assessment of lesions also showed that skin color was darker $\left(-\Delta \mathrm{L}^{*}\right.$ value; $P|\mathrm{t}|<0.001)$, redder $\left(+\Delta \mathrm{a}^{*}\right.$ value; $\left.P|\mathrm{t}|<0.001\right)$, and yellower $\left(+\Delta \mathrm{b}^{*}\right.$ value; $\left.P|\mathrm{t}|<0.001\right)$ in the lesion area compared to nonlesioned skin (Table 2). However, differently from the visual assessment method, the spectrophotometric method was able to detect differences between lesion age categories. Based on the $\Delta \mathrm{L}^{*}$ and $\Delta \mathrm{a}^{*}$ color values, $\mathrm{T} 1$ lesions $(<7 \mathrm{~h}$ old $)$ were darker and redder than T3 lesions ( $P=0.01$ for both color values) and T4 lesions $\left(P<0.001\right.$ and $P=0.003$ for $\Delta \mathrm{L}^{*}$ and $\Delta \mathrm{a}^{*}$ values, respectively). The same trend was observed for $\Delta \mathrm{L}^{*}$ and $\Delta \mathrm{a}^{*}$ color values between $\mathrm{T} 1$ and $\mathrm{T} 2(P$ $=0.06$ and $P=0.08$, respectively). No time-dependent difference was found for $\Delta \mathrm{b}^{*}$, indicator of the yellowness of the lesion $(P>0.10)$. This latter result is not 
Table 2. Effect of the age categories on the delta color values (difference between the skin lesion and the control) as assessed by visual and spectrophotometric color methods

\begin{tabular}{|c|c|c|c|c|c|c|}
\hline \multirow[b]{2}{*}{ Color assessment } & \multicolumn{4}{|c|}{ Age category ${ }^{1}$} & \multirow[b]{2}{*}{ SE } & \multirow[b]{2}{*}{$P$-value } \\
\hline & $\mathrm{T} 1$ & $\mathrm{~T} 2$ & $\mathrm{~T} 3$ & $\mathrm{~T} 4$ & & \\
\hline \multicolumn{7}{|l|}{ Visual } \\
\hline$\Delta$ brightness & $\begin{array}{c}-4.50 \\
(-6.50,-3.00)\end{array}$ & $\begin{array}{c}-4.00 \\
(-5.00,-3.00)\end{array}$ & $\begin{array}{c}-3.00 \\
(-4.00,-2.50)\end{array}$ & $\begin{array}{c}-4.00 \\
(-5.00,-3.00)\end{array}$ & - & 0.34 \\
\hline$\Delta$ hue & $\begin{array}{c}-1.50 \\
(-2.00,-1.00)\end{array}$ & $\begin{array}{c}-1.00 \\
(-2.00,-1.00)\end{array}$ & $\begin{array}{c}-1.00 \\
(-2.00,-1.00)\end{array}$ & $\begin{array}{c}-1.00 \\
(-2.00,-1.00)\end{array}$ & - & 0.87 \\
\hline \multicolumn{7}{|l|}{ Spectrophotometric } \\
\hline$\Delta \mathrm{L}^{*}$ & $-13.16^{\mathrm{aA}}$ & $-9.05 \mathrm{abB}$ & $-8.22^{b}$ & $-6.63^{b}$ & 1.141 & 0.001 \\
\hline$\Delta \mathrm{a}^{*}$ & $15.11^{\mathrm{aA}}$ & $10.62 \mathrm{abB}$ & $9.34^{\mathrm{b}}$ & $8.43^{\mathrm{b}}$ & 1.317 & 0.003 \\
\hline$\Delta \mathrm{b}^{*}$ & 5.85 & 4.99 & 5.38 & 5.04 & 0.589 & 0.71 \\
\hline
\end{tabular}

surprising as the yellow component, which results from the degradation of hemoglobin into bilirubin during the late phases of healing (Hughes et al., 2004b; Mimasaka et al., 2010), is well known as an indicator of lesions older than those assessed in this study. Indeed, the yellow color was observed nearer $72 \mathrm{~h}$ in human adult bruises (Langlois, 2007) or from $5 \mathrm{~d}$ to $3 \mathrm{wk}$ after the injury in child bruises (Mimasaka et al., 2010).

Thus, the spectrophotometric color assessment appears to be a useful method to discriminate between fresh and older lesion ( $<7 \mathrm{~h}$ vs. $>25 \mathrm{~h}$ old $)$ as previously reported in a number of studies on humans (Hughes and Langlois, 2010; Mimasaka et al., 2010; Grossman et al., 2011).

In this study, the efficiency of the use of $\Delta \mathrm{L}^{*}$ or $\Delta \mathrm{a}^{*}$ parameters for the determination of the age of lesions was validated through a diagnostic test. The best threshold value identified for the $\Delta \mathrm{L}^{*}$ was -15 . When a $\Delta \mathrm{L}^{*}$ value higher than the threshold was considered as an indicator of lesions older than $7 \mathrm{~h}$, the diagnostic test presented a sensitivity of 0.40 , a specificity of 0.95 , a PPV of 0.73 , and an NPV of 0.83 . The best threshold value identified for the $\Delta \mathrm{a}^{*}$ was 15 . When a $\Delta \mathrm{a}^{*}$ value lower than the threshold was considered as an indicator of lesions older than $7 \mathrm{~h}$, the diagnostic test presented a sensitivity of 0.50 , a specificity of 0.88 , a PPV of 0.59 , and an NPV of 0.84 . Based on this test, it may be concluded that there was $73 \%$ of a chance that a lesion was old if the $\Delta \mathrm{L}^{*}$ value was higher than -15 and $59 \%$ of a chance that the lesion was old if the $\Delta \mathrm{a}^{*}$ value was less than 15 . However, for both color parameters, the sensitivity values were low, indicating that the test was not sensitive enough to discriminate between fresh and old lesions consistently. Differences in the depth of the lesion and its location on the carcass may limit the efficiency of the spectrophotometric assessment as the thickness of the subcutaneous fat tissue may alter the changes in the bruise color and the speed of the healing process (Mimasaka et al., 2010). The individual variation in the degradation of hemoglobin over time should be also taken into account in the interpretation of the results (Grossman et al., 2011).

\section{Histology and Enzyme Histochemistry}

No difference was found in the necrosis and hemorrhage scores between lesion age categories $(P>$ 0.10 ; Table 3). Conversely, a relationship was found between inflammation score and the age of the lesion $(P<0.001)$ in this study, with a higher proportion of lesions with the highest score (score 2 ) being found in T3 and T4 lesions ( $>25$ h old) compared with T1 lesions $(P=0.001$ and $P<0.001$, respectively). A similar inflammation rate has been also reported in 33-49 h old humans wounds (Takamiya et al., 2008), and in mice, calves, and lambs, skin bruises between 24 and $71 \mathrm{~h}$ after the injury (McCausland and Dougherty, 1978; Takamiya et al., 2005). Erosion/ulceration score also tended to be higher $(P=0.07)$ in T3 and T4 than in T1 lesions (Table 3).

Within the lesion age categories, no difference in the epidermal ATPase and epidermal and dermal ALPase scores was found between the lesioned and the control skin in this study $(P>0.10$; Table 3$)$, suggesting that the use of enzyme histochemical techniques may not be appropriate for the evaluation of the age of a skin lesion. This is likely due to the rather inconsistent appearance of ATPase and ALPase in the stains as previously reported by Betz (1994) and Cecchi (2010). Even if little is known about the role of ALPase in wound healing, this enzyme has been used as a marker for skin wound age determination (Abe et al., 2001; Hawkins and Abrahamse, 2007). An increased expression of ATPase and 
Table 3. Variation of the histological scores and the delta values (difference between the skin lesion and the control) for the enzymatic activities according to lesion age category ${ }^{1}$

\begin{tabular}{|c|c|c|c|c|c|c|}
\hline & \multirow[b]{2}{*}{$\mathrm{N}$} & \multirow[b]{2}{*}{ Age category ${ }^{3}$} & \multicolumn{3}{|c|}{ Score $^{2}$} & \multirow[b]{2}{*}{$P$-value } \\
\hline & & & 0 & 1 & 2 & \\
\hline \multicolumn{7}{|l|}{ Histology } \\
\hline \multirow[t]{4}{*}{ Necrosis } & 78 & $\mathrm{~T} 1$ & 25.00 & 60.00 & 15.00 & 0.16 \\
\hline & & $\mathrm{T} 2$ & 10.00 & 50.00 & 40.00 & \\
\hline & & $\mathrm{T} 3$ & 15.00 & 55.00 & 30.00 & \\
\hline & & $\mathrm{T} 4$ & 11.11 & 44.44 & 44.44 & \\
\hline \multirow[t]{4}{*}{ Erosion/ulceration } & 77 & $\mathrm{~T} 1$ & 50.00 & 35.00 & 15.00 & 0.07 \\
\hline & & $\mathrm{T} 2$ & 15.00 & 50.00 & 35.00 & \\
\hline & & $\mathrm{T} 3$ & 26.32 & 42.11 & 31.58 & \\
\hline & & $\mathrm{T} 4$ & 16.67 & 44.44 & 38.89 & \\
\hline \multirow[t]{4}{*}{ Inflammation } & 78 & $\mathrm{~T} 1$ & 45.00 & 55.00 & 0.00 & $<0.001$ \\
\hline & & $\mathrm{T} 2$ & 20.00 & 50.00 & 30.00 & \\
\hline & & $\mathrm{T} 3$ & 10.00 & 55.00 & 35.00 & \\
\hline & & $\mathrm{T} 4$ & 5.56 & 50.00 & 44.44 & \\
\hline \multirow[t]{4}{*}{ Hemorrhage } & 78 & $\mathrm{~T} 1$ & 15.00 & 75.00 & 10.00 & 0.50 \\
\hline & & $\mathrm{T} 2$ & 25.00 & 65.00 & 10.00 & \\
\hline & & $\mathrm{T} 3$ & 0.00 & 95.00 & 5.00 & \\
\hline & & $\mathrm{T} 4$ & 11.11 & 72.22 & 16.67 & \\
\hline \multicolumn{7}{|l|}{ Enzyme histochemistry } \\
\hline \multirow[t]{4}{*}{$\Delta \mathrm{ALPaseE}^{4}$} & 79 & $\mathrm{~T} 1$ & 50.00 & 50.00 & - & 0.16 \\
\hline & & $\mathrm{T} 2$ & 84.21 & 15.79 & - & \\
\hline & & $\mathrm{T} 3$ & 60.00 & 40.00 & - & \\
\hline & & $\mathrm{T} 4$ & 60.00 & 40.00 & - & \\
\hline \multirow[t]{4}{*}{$\Delta \mathrm{ALPaseD}^{5}$} & 79 & $\mathrm{~T} 1$ & 40.00 & 45.00 & 15.00 & 0.76 \\
\hline & & $\mathrm{T} 2$ & 57.89 & 21.05 & 21.05 & \\
\hline & & $\mathrm{T} 3$ & 40.00 & 55.00 & 5.00 & \\
\hline & & $\mathrm{T} 4$ & 35.00 & 45.00 & 20.00 & \\
\hline \multirow[t]{4}{*}{$\Delta$ ATPase $^{6}$} & 79 & $\mathrm{~T} 1$ & 85.00 & 15.00 & - & 0.73 \\
\hline & & $\mathrm{T} 2$ & 84.21 & 15.79 & - & \\
\hline & & $\mathrm{T} 3$ & 94.74 & 5.26 & - & \\
\hline & & $\mathrm{T} 4$ & 85.00 & 15.00 & - & \\
\hline
\end{tabular}

\footnotetext{
${ }^{1}$ Values represent the percentage of lesions in each age categories according to the score system for the different analyses (100\% in row). The $P$-value corresponds to the Cochran-Mantel-Haenszel test (row mean score).

${ }^{2}$ Scoring system: $0=$ absent; $1=$ minimal to mild; $2=$ moderate to severe lesions for inflammation and hemorrhage. For necrosis and erosion, the system was modified as: $0=0 \% ; 1=<25 \%-<50 \% ; 2=50 \%-100 \%$ of the epidermis. For the enzyme histochemistry, $0=$ delta value of $0 ; 1=$ delta value of 1 or $2 ; 2=$ delta value of 3 or 4 .

${ }^{3}$ Age categories: $\mathrm{T} 1=<7 \mathrm{~h} ; \mathrm{T} 2=7-25 \mathrm{~h} ; \mathrm{T} 3=25-30 \mathrm{~h} ; \mathrm{T} 4=49-54 \mathrm{~h}$.

${ }^{4} \mathrm{ALPaseE}=$ Epidermal Alkaline Phosphatase.

${ }^{5} \mathrm{ALPaseD}=$ Dermal Alkaline Phosphatase.

${ }^{6}$ ATPase $=$ Epidermal Adenosine Triphosphatase.
}

ALPase was reported in $1 \mathrm{~h}$ and $4-8 \mathrm{~h}$ old skin human wounds, respectively, with activities being observed for more than $16 \mathrm{~h}$ for both enzymes (Raekallio, 1972; Dettmeyer, 2011) Psaroudakis et al. (2001) showed an increased presence of ATPase in rabbit wounds from 2 to $20 \mathrm{~h}$ after injury and of ALPase from 3.5 to $32 \mathrm{~h}$ after injury. Differences observed among studies may be due to various factors, such as the type and extent of the injuries (lesion vs. wound), or the skin structure, which is species dependent.

\section{Gene Expression}

Of the 10 tested genes, 6 (CCL2, IL6, ITGA3, SERPINE1, MMP1, and TIMP1) presented a significant time-dependent expression pattern, with the fold change attaining the highest level in T1 lesions and then decreased in older lesions in this study (age category: $P<0.05$; Fig. 2). Conversely, the other 4 genes (TNF $\alpha, I L 8, I L 10$, and COX2) were equally overexpressed, regardless of the lesion age category, resulting in no variation in their expression over time $(P>0.10)$. 

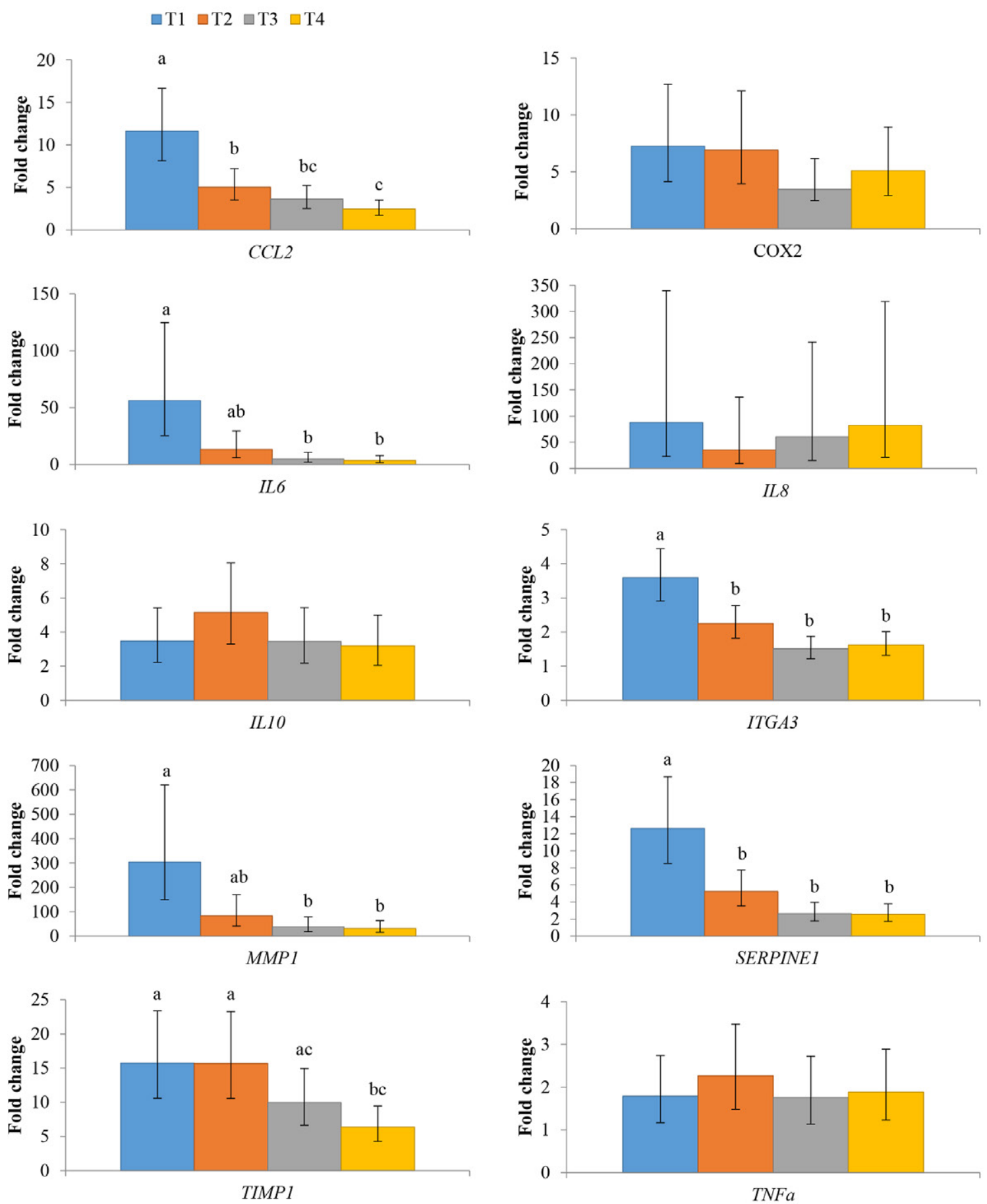

Figure 2. Fold change in gene expression for the 4 age categories of skin lesions. Means within a row with different superscripts differ $(P<0.05)$. The error bars represent the maximum and minimum values in fold change. $\mathrm{T} 1=<7 \mathrm{~h} ; \mathrm{T} 2=7-25 \mathrm{~h}$; $33=25-30 \mathrm{~h}$; T4 $=49-54 \mathrm{~h}$.

When compared with T2 lesions, T1 lesions presented a higher fold change for CCL2 $(P=0.008)$, ITGA3 $(P=0.01)$, and SERPINE1 $(P=0.01)$ genes. Furthermore, a higher $(P<0.001)$ fold change was found in the T1 lesions for CCL2, IL6, ITGA3, MMP1, and SERPINE1 genes when compared with $\mathrm{T} 3$ and $\mathrm{T} 4$ lesions, respectively. No difference was found in the fold change of these genes between T3 and T4 lesion categories $(P>0.10)$. A different expression pattern was found for TIMP1 gene when compared to the oth- er genes, with its fold change being higher $(P=0.01)$ in T1 and T2 lesions compared with T4 lesions. No difference was found in this gene expression between $\mathrm{T} 1$ and $\mathrm{T} 2$ lesions $(P>0.10)$.

Except for CCL2, IL6, and MMP1, to our knowledge, the expression of the genes tested in this study has never been used before for assessing the lesion age in any species, including humans. CCL2 is a chemokine mainly involved in the inflammatory response, controlling the recruitment of monocytes/ 
macrophages (Werner and Grose, 2003; Kondo and Ishida, 2010). Its increased expression found in fresh lesions (T1) in this study is in agreement with other studies assessing skin wound healing in mice (Kondo and Ishida, 2010; Wang et al., 2015). The increased expression within the first few hours after injury of IL6, a proinflammatory cytokine playing an essential early role in the healing response (Lin et al., 2003; Werner and Grose, 2003), agrees with previous results reported by Sato and Ohshima (2000) in mice wound healing where IL6 peaked at $6 \mathrm{~h}$ after injury. However, these results contrast with those by Wang et al. (2015), who reported the highest expression of this gene $1 \mathrm{~d}$ after wounding in humans and mice. Moreover, MMP1, which is associated with inflammation, control of matrix degradation, cell migration (Rohani and Parks, 2015), tissue remodeling, and angiogenesis (Gallant-Behm and Hart, 2006; Wang et al., 2015), was the most expressed gene in this study. Madlener et al. (1998) also reported an increased expression of this gene in mice wounds, but only starting from $1 \mathrm{~d}$ after the injury. The current study provides the first evidence that the expression of this gene increases in more recent lesions ( $<7 \mathrm{~h}$ postinjury).

Previous studies reported that both Itga3 and Timpl genes are involved in the wound healing process in mice (Madlener et al., 1998; Reynolds et al., 2008). A greater level of SERPIN family proteases has been also reported in wound exudates in humans (Eming et al., 2010). Our study clearly shows that these genes are also differently modulated during the healing process of skin lesions. SERPINE1 is known to be involved in stimulating $M M P$ and integrins (Li et al., 2003; Behm et al., 2012) that were mostly expressed in T1 lesions in this study. However, integrins are also involved in the activation of TIMP, an inhibitor of $M M P$ (Gill and Parks, 2008; Behm et al., 2012), which achieved the greatest expression in T3 lesions compared to other genes measured in the present study.

$T N F \alpha, I L 8, I L 10$, and COX2 genes are all involved in the inflammatory response and often in the regulatory process of the other phases of wound healing (Werner and Grose, 2003; Takamiya et al., 2008; Gilroy et al., 1999; Cecchi, 2010). Studies on pigs and mice (Wang et al., 2001; Wang et al., 2015; Wang et al., 2016) reported a greater expression of $T N F \alpha$ in excisional wounds between 1 and $14 \mathrm{~d}$ of age. A similar variation in the expression was expected from IL10, whose expression is promoted by $T N F \alpha$ (Wanidworanun and Strober, 1993). However, its expression level is inconsistently reported in the literature with peaks observed at $60 \mathrm{~min}$ (Ohshima and Sato, 1998), or at $3 \mathrm{~h}$ and $3 \mathrm{~d}$ after the infliction of the lesion (Sato et al., 1999). The expression of IL 8 and COX2 has been reported until 4 $\mathrm{d}$ after wounding in humans (Engelhardt et al., 1998) and from $1 \mathrm{~h}$ to $3 \mathrm{~d}$ in incised skin wound in rabbits (Bai et al., 2008), respectively. In the current study, the lack of difference in the expression of $T N F \alpha, I L 8, I L 10$, and $C O X 2$ between lesion age categories and the high variation in the expression of $I L 8$ within lesion age category suggest the unreliability of these genes as markers for the determination of skin lesion age.

Overall, the combined assessment of MMP1, SERPINE1, IL6, and CCL2 gene expression may be useful to discriminate between fresh and older lesions $(<7 \mathrm{~h}$ vs. $25 \mathrm{~h}$ ), while the analysis of the TIMP1 expression can help distinguish between $<25 \mathrm{~h}$ and $>49 \mathrm{~h}$ old lesions on a pig carcass.

Our results confirm the efficiency of the real-time PCR mRNA analysis for the assessment of the age of lesions as reported in a previous study (Kondo and Ishida, 2010). However, this method may have some limitations under commercial conditions because it is laborious, time-consuming, and expensive (Takamiya et al., 2008).

\section{Multivariate Analysis}

An approach based on the simultaneous analysis of many factors is considered as the best way to develop a reliable method on dating lesions (Cecchi, 2010). Factors used in the FAMD were selected from gene expression analysis (TIMP1, IL6, CCL2, SERPINE1, ITGA3, and $M M P 1)$, the spectrophotometric color analysis $\left(\triangle \mathrm{a}^{*}\right.$ and $\Delta \mathrm{L}^{*}$ color values), and the histological parameters (i.e., inflammation and erosion), based on their relationship with lesion age categories. The multivariate analysis of the selected parameters shows that the variance in the lesion age can be explained by $49.9 \%$ of the combination of Principal 1 (Prin 1) and Principal 2 (Prin 2) components (Fig. 3), which may be attributed to the process of lesion healing. The other $50.1 \%$ of the variance may be related to other factors, such as the severity of the lesion (Barington and Jensen, 2016b), the individual physiological response, the animal body condition (i.e., body weight and fat thickness), and the anatomical location of the lesion (Cecchi, 2010; Mimasaka et al., 2010; Grossman et al., 2011). The position of variables on Prin 1 and 2 in the image (Fig. 3) showed that the lesion age categories are negatively associated with the gene expressions and the spectrophotometric $\Delta \mathrm{a}^{*}$ color value, which indicates that the older the lesion is, the lower the gene expression and the $\Delta \mathrm{a}^{*}$ color value are. In this study, fresh lesions were actually redder and presented a higher gene expression level. The opposite position of the $\Delta \mathrm{L}^{*}$ color vector in relation to the $\Delta \mathrm{a}^{*}$ color value and to all genes vectors may be explained by a negative $L^{*}$ color value, which increases as long as the lesion color gets dark. The 0 and 


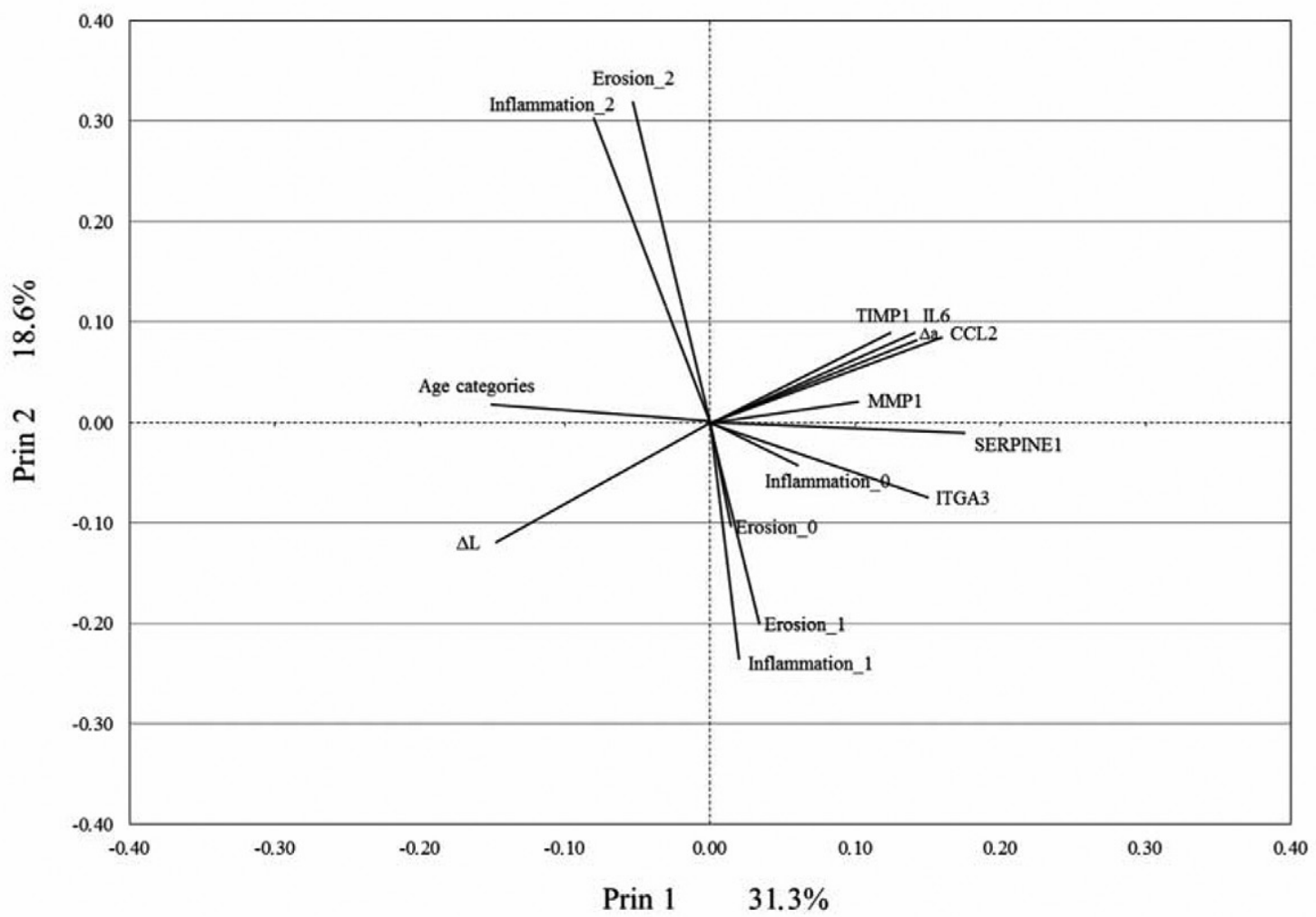

Figure 3. Factorial analysis of mixed data for the selected parameters. The scores 0,1 , and 2 in the erosion and inflammation parameters represent each category of the healing condition of the lesion. The age categories parameter consists of the numerical categories $(1=<7 \mathrm{~h} ; 2=7-25 \mathrm{~h} ; 3=25-30 \mathrm{~h}$; $4=49-54 \mathrm{~h}$ ). Delta $(\Delta)$ values indicate the differences between the lesions and controls for the $\mathrm{L}^{*}$ (lightness) and a* (redness) color parameters.

2 inflammation scores (absence and moderate to severe, respectively) were negatively and positively associated, respectively, with the age categories, indicating that the inflammation response in the skin tissue increased with the age of the lesions. No relationship was found between minimal inflammation rate (score 1) and the age of the lesions, which confirms the lack of variation in the percentage of lesions presenting a minimal or mild inflammation rate in the lesion age categories comparison (Table 3). This result suggests that this degree of inflammation may be more closely related to factors, such as the severity of the lesion or individual physiological response, as previously observed by Barington and Jensen (2016b) in pig bruises.

In summary, the results of the multivariate analysis show the positive association between TIMP1, IL6, and $C C L 2$ gene expression and the $\triangle \mathrm{a}^{*}$ color value and confirm the potential of spectrophotometric color method for the reliable assessment of the age of a lesion.

\section{CONCLUSIONS}

The need to monitor handling and critical areas preslaughter to improve animal welfare and pork quality is of increasing interest in the pork sector and results in the demand for the development of a practical and accurate technique for the determination of the age of lesions on the carcass at slaughter.

Based on the assessment of preslaughter carcass lesions in this study, the spectrophotometric color assessment of the lesion on the carcass appears to be a suitable and rapid technique for discriminating between fresh lesions $(<7 \mathrm{~h})$ occurring between loading and slaughter and old lesions ( $>25 \mathrm{~h}$ old) originating from the farm. However, the high variability in color results, likely due to individual variation in pig body composition (i.e., subcutaneous fat thickness), prevented us from obtaining a color threshold that allows an accurate discrimination between lesion age categories in this study. Further investigations are needed to assess the influence of this factor on the spectrophotometric lesion color measurement.

The analysis of MMP1, SERPINE1, IL6, ITGA3, TIMP1, and CCL2 gene expression and the inflammation response in the skin lesion at slaughter supported the spectrophotometric color results in this study. This relationship shows the potential of these techniques for the validation of on-line objective determination of the lesion age and the usefulness of this type of assessment using the pig as a model for scientific purposes in human studies and for forensic investigation. 


\section{LITERATURE CITED}

Aaslyng, M., P. Brandt, L. Blaabjerg, and S. Støier. 2013. Assessment and incidence of skin damage in slaughter pigs. In: Proc. 59th Intern. Congr. Meat Sci. Technol., Izmir, Turkey.

Abe, T., Y. Abe, Y. Aida, Y. Hara, and K. Maeda. 2001. Extracellular matrix regulates induction of alkaline phosphatase expression by ascorbic acid in human fibroblasts. J. Cell. Physiol. 189:144-151. doi:10.1002/jcp.10011

Bai, R., L. Wan, and M. Shi. 2008. The time-dependent expressions of IL-1 $\beta$, COX-2, MCP-1 mRNA in skin wounds of rabbits. Forensic Sci. Int. 175:193-197. doi:10.1016/j.forsciint.2007.07.006

Bancroft, J. D. 1975. Histochemical techniques. Butterworths, London.

Barington, K., and H. E. Jensen. 2013. Forensic cases of bruises in pigs. Vet. Rec. 173:526. doi:10.1136/vr.101854

Barington, K., and H. E. Jensen. 2016a. A novel, comprehensive, and reproducible porcine model for determining the timing of bruises in forensic pathology. Forensic Sci. Med. Pathol. 12:58 67. doi:10.1007/s12024-016-9744-6

Barington, K., and H. E. Jensen. 2016b. The impact of force on the timing of bruises evaluated in a porcine model. J. Forensic Leg. Med. 40:61-66. doi:10.1016/j.jflm.2016.03.005

Behm, B., P. Babilas, M. Landthaler, and S. Schreml. 2012. Cytokines, chemokines and growth factors in wound healing. J. Eur. Acad. Dermatol. Venereol. 26:812-820. doi:10.1111/j.14683083.2011.04415.x

Betz, P. 1994. Histological and enzyme histochemical parameters for the age estimation of human skin wounds. Int. J. Legal Med. 107:60-68. doi:10.1007/BF01225491

Canadian Council on Animal Care (CCAC). 2009. Guidelines on the care and use of farm animals in research, teaching and testing. Canadian Council on Animal Care, Ottawa, ON, Canada.

Cecchi, R. 2010. Estimating wound age: Looking into the future. Int. J. Legal Med. 124:523-536. doi:10.1007/s00414-010-0505-X

dalla Costa, O. A., L. Faucitano, A. Coldebella, J. V. Ludke, J. V. Peloso, D. Dalla Roza, and M. J. R. Paranhos da Costa. 2007. Effects of the season of the year, truck type and location on truck on skin bruises and meat quality in pigs. Livest. Sci. 107:29-36. doi:10.1016/j.livsci.2006.08.015

Dettmeyer, R. B. 2011. Forensic histopathology: Fundamentals and perspectives. Springer, Berlin. p. 191-209. doi:10.1007/978-3642-20659-7_10

EFSA Panel on Animal Health and Welfare. 2012. Statement on the use of animal-based measures to assess the welfare of animals. EFSA J. 10(6):2767. doi:10.2903/j.efsa.2012.2767.

Eming, S. A., M. Koch, A. Krieger, B. Brachvogel, S. Kreft, L. Bruckner-Tuderman, T. Krieg, J. D. Shannon, and J. W. Fox. 2010. Differential proteomic analysis distinguishes tissue repair biomarker signatures in wound exudates obtained from normal healing and chronic wounds. J. Proteome Res. 9:4758-4766. doi:10.1021/pr100456d

Engelhardt, E., A. Toksoy, M. Goebeler, S. Debus, E.-B. Bröcker, and R. Gillitzer. 1998. Chemokines IL-8, GRO $\alpha$, MCP-1, IP10 , and Mig are sequentially and differentially expressed during phase-specific infiltration of leukocyte subsets in human wound healing. Am. J. Pathol. 153:1849-1860. doi:10.1016/S00029440(10)65699-4

Faucitano, L. 2001. Causes of skin damage to pig carcasses. Can. J. Anim. Sci. 81:39-45. doi:10.4141/A00-031

Gallant-Behm, C. L., and D. A. Hart. 2006. Genetic analysis of skin wound healing and scarring in a porcine model. Wound Repair Regen. 14:46-54. doi:10.1111/j.1524-475X.2005.00087.x
Gill, S. E., and W. C. Parks. 2008. Metalloproteinases and their inhibitors: Regulators of wound healing. Int. J. Biochem. Cell Biol. 40:1334-1347. doi:10.1016/j.biocel.2007.10.024

Gilroy, D. W., P. R. Colville-Nash, D. Willis, J. Chivers, M. J. PaulClark, and D. A. Willoughby. 1999. Inducible cyclooxygenase may have anti-inflammatory properties. Nat. Med. 5:698-701. doi:10.1038/9550

Grossman, S. E., A. Johnston, P. Vanezis, and D. Perrett. 2011. Can we assess the age of bruises? An attempt to develop an objective technique. Med. Sci. Law 51:170-176. doi:10.1258/ msl.2011.010135

Hamdy, M. K., L. E. Kunkle, and F. E. Deatherage. 1957. Bruised tissue. II. Determination of the age of a bruise. J. Anim. Sci. 16:490-495. doi:10.2527/jas1957.162490x

Hawkins, D., and H. Abrahamse. 2007. How should an increase in alkaline phosphatase activity be interpreted? Laser Chem. 2007:1-10. doi:10.1155/2007/49608

Hughes, V. K., P. S. Ellis, T. Burt, E. I. Langlois, and N. Langlois. 2004a. The practical application of reflectance spectrophotometry for the demonstration of haemoglobin and its degradation in bruises. J. Clin. Pathol. 57:355-359. doi:10.1136/ jcp.2003.011445

Hughes, V. K., P. S. Ellis, and N. E. I. Langlois. 2004b. The perception of yellow in bruises. J. Clin. Forensic Med. 11:257-259. doi:10.1016/j.jcfm.2004.01.007

Hughes, V. K., and N. E. I. Langlois. 2010. Use of reflectance spectrophotometry and colorimetry in a general linear model for the determination of the age of bruises. Forensic Sci. Med. Pathol. 6:275-281. doi:10.1007/s12024-010-9171-z

ITP. 1996. Notation des hématomes sur couenne- porcs vivant ou carcasse. Institute Technique du Porc, Rennes, France.

Kondo, T., and Y. Ishida. 2010. Molecular pathology of wound healing. Forensic Sci. Int. 203:93-98. doi:10.1016/j. forsciint.2010.07.004

Langlois, N. E. I. 2007. The science behind the quest to determine the age of bruises: A review of the English language literature. Forensic Sci. Med. Pathol. 3:241-251. doi:10.1007/s12024007-9019-3

Li, W.-Y., S. S. N. Chong, E. Y. Huang, and T.-L. Tuan. 2003. Plasminogen activator/plasmin system: A major player in wound healing? Wound Repair Regen. 11:239-247. doi:10.1046/ j.1524-475X.2003.11402.x

Lin, Z.-Q., T. Kondo, Y. Ishida, T. Takayasu, and N. Mukaida. 2003. Essential involvement of IL-6 in the skin wound-healing process as evidenced by delayed wound healing in IL-6-deficient mice. J. Leukoc. Biol. 73:713-721. doi:10.1189/jlb.0802397

Livak, K. J., and T. D. Schmittgen. 2001. Analysis of relative gene expression data using real-time quantitative PCR and the 2- $\Delta \Delta \mathrm{CT}$ method. Methods 25:402-408. doi:10.1006/ meth.2001.1262

Madlener, M., W. C. Parks, and S. Werner. 1998. Matrix metalloproteinases (MMPs) and their physiological inhibitors (TIMPs) are differentially expressed during excisional skin wound repair. Exp. Cell Res. 242:201-210. doi:10.1006/excr.1998.4049

McCausland, I. P., and R. Dougherty. 1978. Histological ageing of bruises in lambs and calves. Aust. Vet. J. 54:525-527. doi:10.1111/j.1751-0813.1978.tb00322.x

Mimasaka, S., M. Ohtani, N. Kuroda, and S. Tsunenari. 2010. Evaluating the age of bruises in children spectrophotometric evaluation of the age of bruises in children: Measuring changes in bruise color as an indicator of child physical abuse. Tohoku J. Exp. Med. 220:171-175. doi:10.1620/tjem.220.171 
MLC. 1985. Concern at rindside damage in pigs. Meat and Marketing Tech. Notes No. 4, Milton Keynes, Meat and Livestock Commission, Bletchley, UK, p. 14-16.

Munro, R., and H. M. C. Munro. 2013. Some challenges in forensic veterinary pathology: A review. J. Comp. Pathol. 149:57-73. doi:10.1016/j.jcpa.2012.10.001

Ohshima, T., and Y. Sato. 1998. Time-dependent expression of interleukin-10 (IL-10) mRNA during the early phase of skin wound healing as a possible indicator of wound vitality. Int. J. Legal Med. 111:251-255. doi:10.1007/s004140050163

Parikh, R., A. Mathai, S. Parikh, G. Chandra Sekhar, and R. Thomas. 2008. Understanding and using sensitivity, specificity and predictive values. Indian J. Ophthalmol. 56:45-50. doi:10.4103/0301-4738.37595

Psaroudakis, K., M. N. Tzatzarakis, A. M. Tsatsakis, and M. N. Michalodimitrakis. 2001. The application of histochemical methods to the age evaluation of skin wounds : Experimental study in rabbits. Am. J. Forensic Med. Pathol. 22(4):341-345. doi:10.1097/00000433-200112000-00002

Raekallio, J. 1972. Determination of the age of wounds by histochemical and biochemical methods. Forensic Sci. 1:3-16. doi:10.1016/0300-9432(72)90144-6

Reynolds, L. E., F. J. Conti, R. Silva, S. D. Robinson, V. Iyer, R. Rudling, B. Cross, E. Nye, I. R. Hart, C. M. Dipersio, and K. M. Hodivala-Dilke. 2008. Alpha3beta1 integrin-controlled Smad7 regulates reepithelialization during wound healing in mice. J. Clin. Invest. 118:965-974. doi:10.1172/JCI33538

Rocha, L. M., A. M. Bridi, P. Mormède, A. V. Weschenfelder, N. Devillers, W. Bertoloni, and L. Faucitano. 2013. Effects of ractopamine administration and castration method on the response to pre-slaughter stress and carcass and meat quality in pigs of two Pietrain genotypes. J. Anim. Sci. 91:3965-3977. doi:10.2527/jas.2012-6058

Rohani, M. G., and W. C. Parks. 2015. Matrix remodeling by MMPs during wound repair. Matrix Biol. 44-46:113-121. doi:10.1016/j.matbio.2015.03.002

Sato, Y., T. Ohshima, and T. Kondo. 1999. Regulatory role of endogenous interleukin-10 in cutaneous inflammatory response of murine wound healing. Biochem. Biophys. Res. Commun. 265:194-199. doi:10.1006/bbrc.1999.1455

Sato, Y., and T. Ohshima. 2000. The expression of mRNA of proinflammatory cytokines during skin wound healing in mice: A preliminary study for forensic wound age estimation (II). Int. J. Legal Med. 113:140-145. doi:10.1007/s004140050285

Scafide, K. R. N. 2012. Determining the relationship between skin color, sex, and subcutaneous fat and the change in bruise color over time. Ph.D. thesis, The Johns Hopkins Univ., Baltimore, MD.
Strappini, A. C., J. H. M. Metz, C. B. Gallo, and B. Kemp. 2009. Origin and assessment of bruises in beef cattle at slaughter. Animal 3:728-736. doi:10.1017/S1751731109004091

Takamiya, M., K. Saigusa, R. Kumagai, N. Nakayashiki, and Y. Aoki. 2005. Studies on mRNA expression of tissue-type plasminogen activator in bruises for wound age estimation. Int. J. Legal Med. 119:16-21. doi:10.1007/s00414-004-0453-4

Takamiya, M., S. Fujita, K. Saigusa, and Y. Aoki. 2008. Simultaneous detection of eight cytokines in human dermal wounds with a multiplex bead-based immunoassay for wound age estimation. Int. J. Legal Med. 122:143-148. doi:10.1007/s00414-007-0183-5

Varón-Álvarez, L., M. Romero, and J. Sánchez. 2014. Caracterización de las contusiones cutáneas e identificación de factores de riesgo durante el manejo presacrificio de cerdos comerciales. Arch. Med. Vet. 46:93-101. doi:10.4067/S0301732X2014000100013

Vitali, M., S. Conte, G. Martelli, M. Lessard, and L. Faucitano. 2017. Which genes are the best indicators for lesion age determination on the pig carcass? A preliminary study. In: Proc. 7th Int. Conf. on the Assessment of Welfare of Animals at Farm and Group Level (WAFL), September 5-8, Wageningen, the Netherlands.

Wang, J. F., M. E. Olson, C. R. Reno, J. B. Wright, and D. A. Hart. 2001. The pig as a model for excisional skin wound healing: Characterization of the molecular and cellular biology, and bacteriology of the healing process. Comp. Med. 51:341-348.

Wang, Y., Y. Yamamoto, Y. Kuninaka, T. Kondo, and F. Furukawa. 2015. Forensic potential of MMPs and CC chemokines for wound age determination. J. Forensic Sci. 60:1511-1515. doi:10.1111/1556-4029.12831

Wang, L. L., R. Zhao, C. S. Liu, M. Liu, S. S. Li, J. Y. Li, S. K. Jiang, M. Zhang, Z. L. Tian, M. Wang, M. Z. Zhang, and D. W. Guan. 2016. A fundamental study on the dynamics of multiple biomarkers in mouse excisional wounds for wound age estimation. J. Forensic Leg. Med. 39:138-146. doi:10.1016/j. jflm.2016.01.027

Wanidworanun, C., and W. Strober. 1993. Predominant role of tumor necrosis factor-alpha in human monocyte IL-10 synthesis. J. Immunol. 151:6853-6861.

Welfare Quality 2009. Welfare Quality ${ }^{\circledR}$ assessment protocol for pigs (sows and piglets, growing and finishing pigs). Welfare Quality ${ }^{\circledR}$ Consortium, Lelystad, the Netherlands.

Werner, S., and R. Grose. 2003. Regulation of wound healing by growth factors and cytokines. Physiol. Rev. 83:835-870. doi:10.1152/physrev.00031.2002 